\title{
RESISTÊNCIA NAS CHAPADAS DO BAIXO PARNAÍBA: CONFLITOS DE LÓGICAS ENTRE A SILVICULTURA E OS CAMPONESES DO POVOADO TODOS OS SANTOS EM URBANO SANTOS - MARANHÃO
}

Adielson Correia Botelho ${ }^{1}$ Francisco Amaro Gomes de Alencar $^{2}$

Resumo: O Baixo Parnaíba, no Maranhão, sofre com a expansão do capital agrícola da silvicultura, em virtude de complexos de ações públicas e privadas voltado para à exportação da commodity. Essas ações resultam nos diferentes usos do território, por camponeses e silvicultores, que passam a disputá-lo e, consequentemente, entram em conflito. Para o estudo, fez-se a revisão de literatura, trabalho de campo e entrevistas com camponeses, que ajudou nos fundamentos empíricos para 0 estudo. Contrariando os desenvolvimentistas, percebeu-se que o avanço dos eucaliptais contribuiu para profundas mudanças do cotidiano das atividades desses camponeses que implica na destruição do seu modo vida.

Palavras-chave: Lógicas distintas. Território. Resistência Camponesa. Silvicultura. Todos os Santos.

\section{RESISTANCE IN LOW PARNAÍBA CHAPADES: LOGICAL CONFLICTS BETWEEN ASYLVICULTURE AND THE PEOPLE OF POVOADOOS TODOS OS SANTOS IN URBANO SANTOS - MARANHÃO}

\begin{abstract}
Baixo Parnaíba, in Maranhão, suffers from the expansion of the agricultural capital of forestry, due to complex public and private actions aimed at exporting the commodity. These actions result in the different uses of the territory, by peasants and foresters, that start to dispute it and, consequently, they come into conflict. For the study, literature review, field work and interviews with peasants were carried out, which helped in the empirical foundations for the study. Contrary to the developmentalists, it was noticed that the advance of the eucalyptus contributed to deep changes of the daily life of the activities of these peasants that implies in the destruction of their way life.
\end{abstract}

Keywords: Different Logic. Territory. Peasant Resistance. Forestry. Todos os

Santos.

\section{RESISTENCIA EN LAS CHAPADAS DEL BAJO PARNAÍBA: CONFLICTOS DE LÓGICAS ENTRE ASILVICULTURA Y LOS CAMPESINOS DEL PUEBLO TODOS OS SANTOS EN URBANO SANTOS - MARANHÃO}

Resumen: El Bajo Parnaíba, en Maranhão, sufre con la expansión del capital agrícola de la silvicultura, en virtud de complejos de acciones públicas y privadas orientado hacia la exportación de la commodity. Estas acciones resultan en los diferentes usos del territorio, por campesinos y silvicultores, que pasan a disputarlo $y$, consecuentemente, entran en conflicto. Para el estudio, se hizo la revisión de literatura, trabajo de campo y entrevistas con campesinos, que ayudó en los

\footnotetext{
1 Universidade Estadual de Campinas, Programa de Pós Graduação em Geografia, Campinas, Brasil, adielsonbotelho@hotmail.com, https://orcid.org/0000-0002-1825-0097

2 Universidade Federal do Ceará, Programa de Pós Graduação em Geografia, Fortaleza, Brasil, famaro@gmail.com, https://orcid.org/0000-0002-1825-0097
} 
fundamentos empíricos para el estudio. Contrariando a los desarrollistas, se percibió que el avance de los eucaliptales contribuyó a profundos cambios de lo cotidiano de las actividades de esos campesinos que implica la destrucción de su modo de la vida.

Palabras clave: Lógicas distintas. Territorio. Resistencia Campesina. La silvicultura. Todos os Santos.

\section{Introdução}

Localizado no Leste Maranhense, o município de Urbano Santos, assim como a sua região, tornou-se um ponto estratégico para o implantação e expansão de produtos agrícolas, principalmente do eucalipto e da soja, atraindo produtores de diversas regiões do país. Tal localização, associada a uma extensa área de cerrado, suscitou a instalação de empresas silvicultoras e produtores de soja conhecidos genericamente por "Gaúchos3" a partir da décadas de 1980 e 1990, respectivamente, culminando, dessa forma, na especulação do mercado de terras, na qual passaram, literalmente, o cercar os povoados camponesas de campos de soja e eucalipto, entre eles o povoado 4 Todos os Santos, objeto de análise deste estudo. Como resultando, emerge o conflitos pelas distintas lógicas de usufruto e apropriação do território dos camponeses, que oferecem resistência frente à territorialidade do agronegócio, em face das profundas alterações no seu modo de vida.

Partindo da premissa cujas formas de organização camponesa do espaço são desconsideradas por projeto de expansão de commodities, o Baixo Parnaíba tornouse um vetor de embates. A partir dessa proposição, questionamos: há resistência camponesa? Se sim, quais formas de luta? Qual a posição do Estado (municipal, estadual, federal) para dirimir os conflitos territoriais que insurgem e acirram a conflagração já existente no Baixo Parnaíba (Leste Maranhense), de modo particular no povoado Todos os Santos, objeto da presente análise?

Com relação a ideia de centrar a realização trabalhos de campo no Povoado Todos os Santos, no município de Urbano Santos/MA, decorre das visitas técnicas

\footnotetext{
${ }^{3}$ Denominação dada ao migrante do Centro-Sul do país (sulista), pelos maranhenses do Sul e Leste do estado (MA). Para melhor entendimento ler o terceiro capítulo, "Os Gaúchos" (p. 71-102), da dissertação de mestrado de Rafael Bezerra Gaspar, intitulada "O eldorado dos gaúchos".

${ }^{4}$ O termo povoado será utilizado para indicar a unidade territorial, delimitada por fronteiras consensualmente acatadas por seus moradores e reconhecida pelos vizinhos, onde estão situadas as moradias e demais edificações (casas de forno, casas de festa, igrejas, escolas, estabelecimentos comerciais, postos de saúde, quando existentes, e outros) e as áreas de trabalho. Em algumas situações, as áreas de trabalho das famílias de um povoado podem se encontrar em outras localidades. Serão grafados em itálico, termos nativos, como povoado, chapadas e outros ou de utilização genérica, como gaúchos e outros. Também serão grafados em itálico em expressões como comunidades tradicionais, quilombolas e outras, que representam conceitos referidos a categorias jurídicas (PAULA ANDRADE, 2012, p. 45).
} 
realizadas em 2010, 2011, 2013 e 2016; das discussões realizadas no GERUR ${ }^{5}$; durante 0 mestrado ${ }^{6}$; das conversas com as lideranças do Fórum Carajás e relação de confiança.

O Povoado de Todos os Santos é caracterizado por ser um núcleo residencial, em torno do qual são estabelecidas as roças e demais atividades econômicas e sociais. A alternância do uso das formações florestais (mato, carrasco, chapada e baixos) exige do camponês certa mobilidade espacial para suas atividades (agricultura, extração vegetal, pecuária, coleta, dentre outros), sendo que o âmbito desta mobilidade se define pelos limites do povoado. Em relação ao topônimo, Todos os Santos, se dá pelo fato de uma das primeiras moradoras ter começado a promover uma festa em honra de todos os santos e mártires, conhecidos ou não pela Igreja Católica, no dia 02 de novembro. "Uma das moradoras mais antigas trouxe um quadro com todos os santos, tinha a imagem de todos os santos e começou a fazer o festejo de todos os santos e aí batizou o lugar a partir de então, denominado de "Todos os Santos", segundo o camponês que nos concedeu entrevista em 2016.

Todos os Santos possui 54 casas, a maioria construída a partir de blocos de argila conhecidos localmente por adobe, outras são de alvenaria, no período da pesquisa, havia seis casas vazias. São 66 famílias e 137 pessoas no total, entre crianças, adultos e idosos. Consideramos aqui como noção de família (nuclear ou conjugal) é formada, Segundo Eric Wolf, pelo homem e a mulher casados e a sua prole, enquanto as famílias extensas agrupam em uma única estrutura certo número de famílias nucleares (WOLF, 1970, p. 88). O menor número de casas em relação ao número de famílias justifica-se que dentro de algumas casas residem mais de uma família, consistindo em uma das variantes do que Wolf entende por família extensa.

Todos os Santos localiza-se (Figura 01), ao sul da sede do município, há 38 $\mathrm{km}$, o acesso é feito através de estradas vicinais de chão batido, em alguns trechos, por "varedas". As motocicletas são um dos principais meios de transporte utilizado pelos moradores do povoado para se deslocarem até à sede de Urbano Santos ou Chapadinha. Além das motocicletas, há ainda um micro-ônibus que faz "linha" para a sede, três vezes por semana. Haja vistas, que todos os serviços são realizados fora do povoado, por exemplo, consultas médicas, banco, farmácia dentre outros.

\footnotetext{
5 Grupo de Estudos Rurais e Urbanos - GERUR, vinculado ao Programa de Pós Graduação em Sociologia da Universidade Federal do Maranhão - UFMA.

6 Programa de Pós Graduação em Geografia da Universidade Federal do Ceará - UFC.
} 
Quanto à sua infraestrutura, o povoado conta com: uma escola municipal de educação básica; uma capela; comércio e bar; um campo de futebol; barracão de festas; uma oficina motocicletas; doze casas de farinha (unidades de beneficiamento da mandioca) e dois alambiques (unidades de fabricação de aguardente da mandioca conhecido por tiquira). Possui energia elétrica e serviço de água encanada, oriunda de um poço artesiano, alguns moradores têm poços (artesanal) particular no quintal.

\section{Figura 01 - Mapa de localização do povoado Todos os Santos}

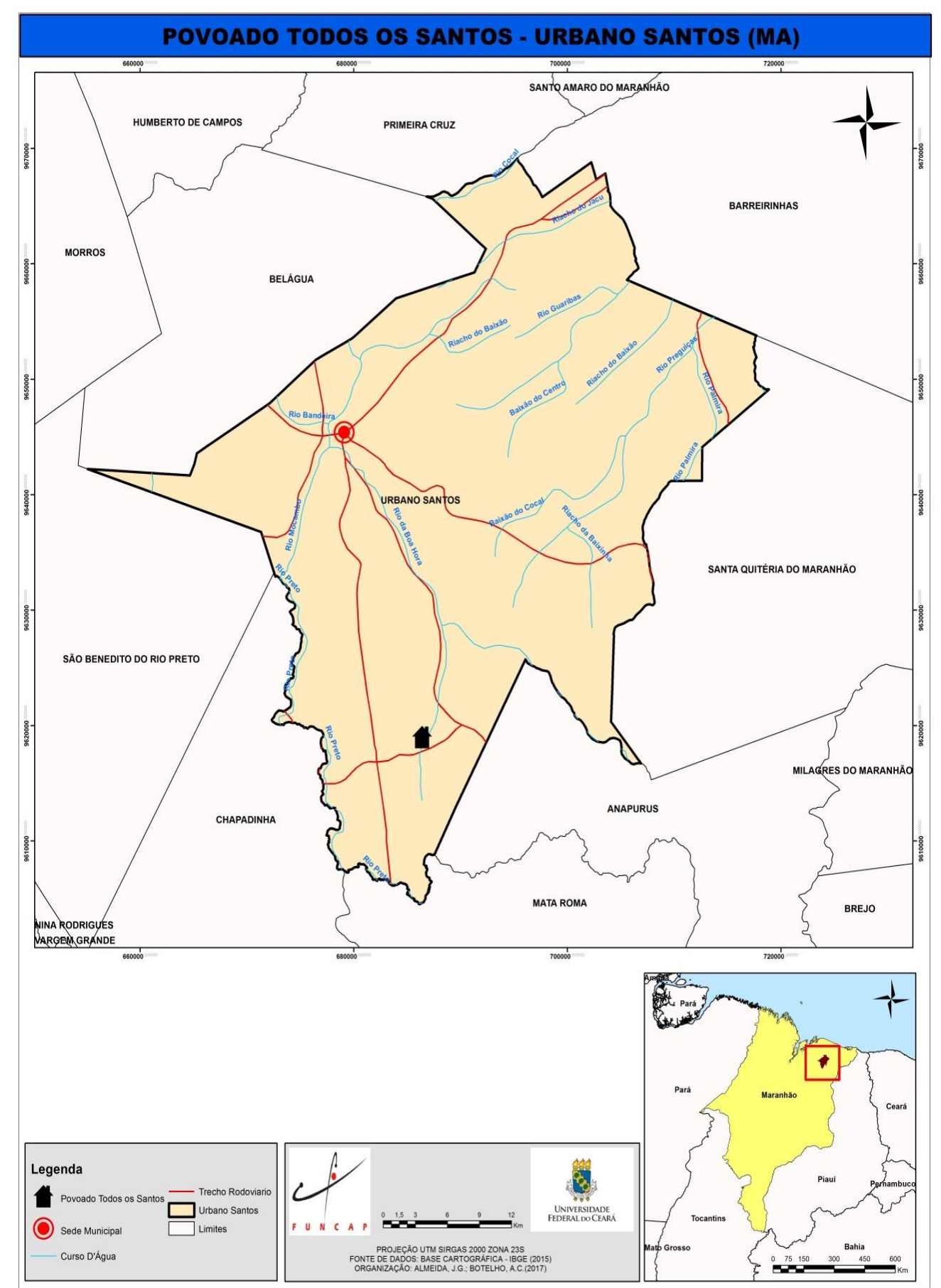


Para a realização deste trabalho utilizamos alguns procedimentos metodológicos. Primeiro, foram feitos levantamento e análise de material bibliográfico enfocando temas como espaço, território, campesinato, agricultura; coleta de dados secundários em páginas eletrônicas na internet do IBGE (SIDRA/Censo Agropecuário e Produção Agrícola Municipal); das empresas envolvidas com os Projetos Florestais (MARGUSA/SUZANO Papel e Celulose; ONG's e outros); visitas técnicas com o objetivo de entrevistar moradores, fazer fotografias, marcas pontos com GPS.

A primeira pesquisa ocorreu em 2010 com o projeto "Campesinato e Crise Ecológica - impactos sociais da sojicultura para segmentos camponeses no Leste Maranhense" nos municípios de São Benedito do Rio Preto, Duque Bacelar e Coelho Neto. A segunda em 2011 pelo "Levantamento dos Conflitos Socioambientais no Baixo Parnaíba Maranhense". A terceira em 2013, para o trabalho de monografia ${ }^{7}$, e, a última, em função da pesquisa de mestrado ${ }^{8}$ em 2016. Outro momento importante da pesquisa foi o levantamento da situação dos trabalhadores atingidos ${ }^{9}$ pelas ações da Suzano Papel e Celulose (e subsidiárias) e Gaúchos, envolvidos no agronegócio da soja. O estudo solicitado e apoiado pelas entidades: Sociedade Maranhense de Direitos Humanos (SMDH), Fórum em Defesa da Vida e do Baixo Parnaíba (FDVBP), Centro de Defesa e Promoções dos Direitos da Cidadania (CEDEPRODC) e lideranças locais dos povoados nos municípios citados.

Além dos contatos e dos laços de confiança construídos com as famílias durante os anos de investigação, as viagens por esses povoados serviram também para dar uma visão geral da situação das famílias do Baixo Parnaíba. Estes trabalhos de campos foram fundamentais para a escolha desse território como universo empírico deste trabalho, especialmente, em março de 2011, quando da segunda etapa do levantamento, em Urbano Santos, no povoado Todos os Santos. Pois ali encontrei situações limites, com a extinção completa do rio Chibél, que servia o povoado, bem como as implicações deste relacionadas a outras atividades

\footnotetext{
7 Monografia, com título "Repercussões dos conflitos socioambientais no Leste Maranhense", defendida/apresentado ao Departamento de Geografia da Universidade Federal do Maranhão.

8 Dissertação, com o título "Resistência camponesa entre carrasco, chapada e mato no Baixo Parnaíba, Maranhão" apresentada/defendida ao Programa de Pós Graduação em Geografia da Universidade Federal do Ceará.

${ }^{9}$ Isto é, que perderam ou estão em vistas de perder suas territorialidades de referência, os memoriais descritivos dos decretos de desapropriação por utilidade pública funcionam como fonte, bem como os dados arrolados pelos movimentos sociais respectivos (ALMEIDA, 2004).
} 
econômicas, principalmente a agricultura, e as demais: caça, pesca, coleta de frutos e extração vegetais.

O texto compõe-se de cinco partes, incluindo está, na qual buscamos brevemente apresentar o presente trabalho e o percurso metodológico desenvolvido, seguida da seção em que são apresentadas condições de inserção dos projetos de silvicultura no Baixo Parnaíba, Na terceira parte, as formas de manutenção da condição camponesa, especialmente nas áreas conhecidas por chapadas, no Baixo Parnaíba, onde está localizado o povoado Todos os Santos, recorte espacial escolhido para a realização da pesquisa. Na quarta parte, buscamos chamar atenção para às formas resistências e lutas pelas quais os camponeses estão conseguindo se manter na/pela terra. Na quinta e última parte, apresentamos as considerações finais, onde reafirmamos a importância da análise da territorialização do capital no Baixo Parnaíba e Todos os Santos como elemento fundamental para a compreensão dos conflitos e das dinâmicas atuais que envolvem dois diferentes sistemas: o agronegócio e o campesinato.

\section{O agronegócio do eucalipto no Baixo Parnaíba e suas consequências para os camponeses de Todos os Santos}

Ao longo do século XX, o campo brasileiro, passou por amplas e diferentes transformações que tinham como um dos objetivos o desenvolvimento econômico de acordo com as exigências do mercado capitalista globalizado. O fluxo de capital, nacional e estrangeiro, injetado no agronegócio por agentes e empresas privadas em consonância com o Estado brasileiro possibilitou uma rápida difusão da agricultura moderna a partir do Centro-Sul brasileiro até as áreas periféricas, ao longo do cinturão da fronteira agrícola, que envolve a Amazônia e o Cerrado das regiões Norte, Nordeste e Centro-Oeste.

Aliado a isso, o reforço da política de apoio à exportação agrícolas da soja, algodão, carne entre outros produtos agrícola pelo governo brasileiro e, pelo boom da economia chinesa, que funcionou, segundo Acioly et al. (2011), como o principal indutor externo da expansão da produção agropecuária. Assim, conforme Carneiro (2013) a intensificação desse processo se deu a partir de 1995, com o crescimento da demanda global por commodites agrícolas e a consequente expansão dos interesses empresariais e do mercado de terras. 
Para Carneiro (2013) esse momento pode ser caracterizado pela importância e posterior declínio da política de incentivos fiscais (FINAN, FINOR) e pela política de créditos agrícolas e da grande disponibilidade de terras nos chamados "vazios econômicos". Trata-se de um momento de valorização da grande propriedade fundiária, através de políticas conservadora da agricultura (SILVA, 1981).

Embora o enfoque espacial do estudo seja o Baixo Parnaíba, é preciso atentar para a mesorregião Leste Maranhense, uma vez que a mesma se apresenta como o "eldorado do agronegócio" (MASSEY; FERGUSON, 2007; OLIVEIRA, 2015), em decorrência da proximidade geográfica a portos de grande movimentação, como o de Itaqui, em São Luís, distante $300 \mathrm{~km}$ de Chapadinha. Tal proximidade do ponto de escoamento para outros países apresentou se como grande vantagem, em termos de custos e logística, já que o outro polo graneleiro do estado, localizado no Sul Maranhense, e cuja cidade principal é Balsas, encontra-se a $800 \mathrm{~km}$ daquele porto (GASPAR, 2014).

Se a década de 1970 foi fundamental para um esboço do uso da terra rumo à pecuária empresarial, as de 1980 e 1990 foram dominadas pela chegada e avanço da soja e, também, da silvicultura de eucalipto em escala industrial. Nesse período surge Programa do Grande Carajás/PGC, cujo objetivo era o desenvolvimento econômico e social de regiões do Maranhão, Piauí e Tocantins. Tal atividade econômica, para Carneiro (2013) foi planejada para o fomento e expansão na chamada área de influência da "Estrada de Ferro Carajás (EFC)", cujo resultado, culminou, no plantio em larga escala de eucalipto.

Ainda de acordo com Carneiro (2013), no caso maranhense, o Projeto Grande Carajás, significou o fomento à expansão, além da sojicultora, dos plantios de eucalipto para o abastecimento da produção siderúrgica, cujos principais efeitos serão o aquecimento do mercado de terras e processos de expropriação camponesa tanto no Oeste, quando no Leste do estado. Para o mesmo autor, o desenvolvimento inicial da silvicultura de eucalipto no Maranhão estava:

Presente no planejamento governamental para a região desde os primeiros documentos do Programa Grande Carajás, o desenvolvimento do plantio de eucalipto ganhou força com os lançamentos pela Vale, no ano de 1990, do Programa de Polos Florestais, que previa o reflorestamento ou plantio, num prazo inicial de dez anos, de um milhão de hectares de espécies florestais do gênero eucalyptus, em fazendas localizadas preferencialmente na segunda parte (trechos entre Açailândia e Santa Inês) da área de influência da Estrada de ferro Carajás (CARNEIRO, 2013, p. 53). 
Cabe ressaltar que, até o final dos anos 1980, a produção de ferro gusa a carvão vegetal concentrou-se quase que exclusivamente no estado de Minas Gerais, foi somente na década seguinte que foram fundadas as primeiras unidades fabris na Amazônia oriental, localizadas nos municípios de Açailândia/MA e Marabá/PA (CARNEIRO 2013). No entanto, em algumas áreas do Maranhão já havia plantações da espécie na região de Urbano Santos, no Baixo Parnaíba.

O Maranhão se destaca, enquanto "plataforma de exportação" de commodites agrícolas com a expansão da soja, cana-de-açúcar e florestais, o incremento dos plantios de eucalipto para o abastecimento da produção de ferro gusa e, mais recentemente, para o suprimento de duas unidades industriais de produção de celulose e para uma unidade de produção de pellets de madeira anunciadas pelo grupo Suzano de Papel e Celulose (CARNEIRO, 2013, p. 23).

O resultado desses projetos governamental para Mesquita (2011) é uma avalanche de produtores "modernos" em segmentos do campo maranhense, com destaque para o plantio, em grande escala de soja e do eucalipto, voltados para atender a uma demanda internacional por commodities (grãos e minérios - oriundo de açarias no oeste do estado, cujo combustível, utilizado para a operação é o eucalipto -, celulose) induzida, sobretudo, pelo forte crescimento da China nos últimos 20 anos.

Desde então, a silvicultura vem se expandindo, em 2014, havia 207.448 hectares de área plantada, no ano seguinte, segundo dados do IBGE e ABRAF, essa área cresceu para 214.094 hectares em 48 municípios maranhenses produzem eucalipto, alguns em pequenas escala, a exemplo de Nova lorque, com 5 hectares, enquanto que, em Grajaú (45.059), Açailândia (35.296), Barra do Corda (23.390), São Pedro da Água Branca (12.288), Urbano Santos (9.432) se destacam como os cinco maiores áreas plantadas por hectares.

Levando em consideração os dois principais produtos da silvicultura de eucalipto, tora em madeira e carvão vegetal, produzidos em Urbano Santos, entre os anos de 1990 e 2015 aconteceram alguns momentos de declínio, principalmente no período de 1997 e 2001. No entanto, no ano seguinte, 2002, o crescimento até 2008, foi eminente, com uma leve freada, especialmente com a produção de madeira em tora, em decorrência da crise mundial daquele ano (Gráfico 01). 


\section{Gráfico 01: Quantidade produzida da extração vegetal de produto extrativo (1990 a 2015) em Urbano Santos/MA}

Evolução da quantidade produzida na extração vegetal em Urbano Santos /MA (1990-2015)

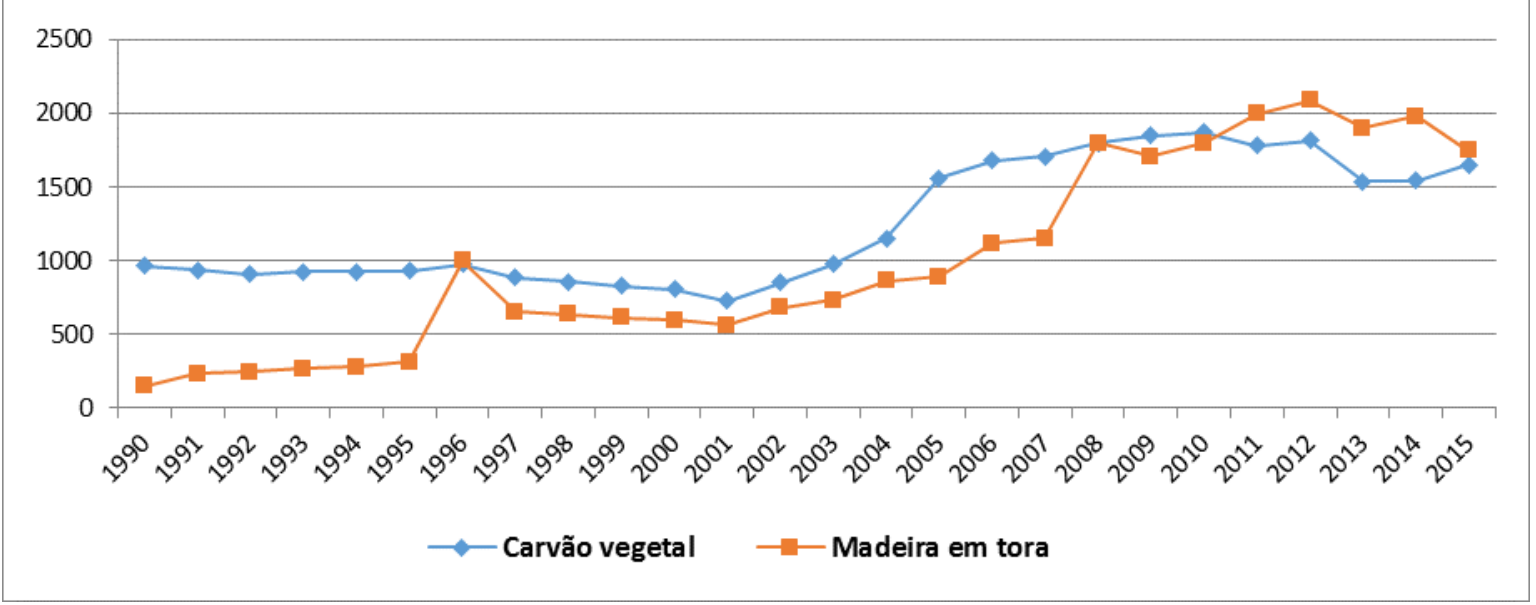

Fonte: IBGE - Produção da Extração Vegetal e da Silvicultura.

A repercussão imediata desse conjunto de projetos desenvolvimentistas, especificamente da silvicultura empresarial, apresenta transformações semelhantes para a estrutura fundiária e o mercado de trabalho agrícola, pois fazem uso predatório dos recursos naturais, promovem a concentração fundiária, e produzem empregos de baixa qualidade (CARNEIRO, 2013).

Conforme Mesquita (2011) essas transformações recentes, ocasionadas pelo movimento de expansão e contração das culturas alimentares, destacando-se o arroz, mostra que os alimentos, ao longo da década de 1980 e 1990, cederam espaço para a pecuária e lavouras comerciais permanentes, caso da silvicultura. Ainda segundo o autor:

As perdas ocorreram em diversas microrregiões e municípios do estado, especialmente naqueles onde essas atividades se concentravam e/ou se concentram, a substituição se fez mais acentuada na pecuária, embora também tenha sio intensa nos municípios que sediam grandes empreendimentos capitalistas, caso de Imperatriz [pecuária, eucalipto], Balsas [soja], Açailândia [pecuária], Coelho Neto [cana-de-açúcar] e Urbano Santos [eucalipto] (MESQUITA, 1998, p. 56).

Outro resultado desse processo de "modernização" reside no elevado grau das contradições econômicas e sociais dessas regiões, pois criam as condições para que alguns moradores dessas áreas optem pela venda de suas pequenas/médias propriedades, isso quando as terras não são açambarcadas através do processo de grilagem ou simplesmente disponibilizadas pelo Estado. 
As justificativas apresentadas por empresas florestais, são que esses empreendimentos representam alternativas para geração de emprego e renda, funcionando como propulsores do "desenvolvimento" local e regional. Sem seu principal instrumento de trabalho, a terra o trabalhador terá de vender sua força de trabalho às empresas silvicultoras, cujas detém, agora, seu principal meio de sobrevivência (a terra). Resta, então, aos moradores, por fazer o chamado "fichamento nas firmas". Perante desse novo contexto destaca-se, ai, o assalariamento em trabalhos nas condições mais precárias, com baixos salários, exaustiva jornada de trabalho que chegam há doze horas por dia, sem direito de receber "hora extra" e ainda são obrigados a aplicarem inseticida nas plantações sem os equipamentos obrigatórios resultando com graves problemas de saúde.

A última opção desses grupos tem sido a migração como necessidade de sua reprodução, conforme Oliveira (2001) a luta pela fração do território distante como alternativa para continuar camponês. Espaço e tempo unem-se dialeticamente na explicação desse processo. Quando essa possibilidade de recuperar encontra novas formas de luta para abrir acesso à terra camponesa onde ela se tornou capitalista.

Em Urbano Santos, a exemplo que acontece em praticamente todos os municípios da região, o declínio da população rural tem sido eminente, pois em 1980 a população rural representava, de acordo com o IBGE, mais de $85 \%$ da população total, em 1991 esse percentual caiu para 70\%, nos Censos seguintes, em 2000 e 2010, esse percentual era de 38\% e 29\% respectivamente. Diante desse quadro, Lévi-Strauss (1973), enfatiza que a "modernização" é acompanhada por uma tendência à concentração da propriedade e da comercialização da terra, daí ocorre uma verdadeira "fabricação de marginais".

Os impactos de projetos de desenvolvimento têm provocado não apenas a "migração em massa" para as cidades, mas uma série de conflitos ambientais (ACSELRAD, 2004) e, principalmente, sociais. Estes são o resultado do confronto de lógicas distintas de apropriação do território. Tais lógicas são, por um lado, a dos grupos sociais atingidos e, na outra ponta, os que gerenciam os projetos de desenvolvimento. O confronto configura um contexto de disputas pela terra envolvendo diferentes formas de significação do modo de vida e reprodução material e simbólica a partir dos atores sociais neles inseridos.

Nesse contexto, o campesinato passa por violentas crises de sobrevivência e reprodução no mundo contemporâneo. Como dispõem Moura (1998, p.47): 
Enfrenta tanto a ameaça de expropriação definitiva, que ocorre em determinados contextos e que significa a perda total de suas condições de reprodução, quanto uma expropriação paulatina, que a cada dia o torna mais explorado, mais submetido, mais dependente da economia capitalista.

No trabalho de campo, realizado em outubro de 2016, segundo relatos dos camponeses, as empresas proíbem o acesso e/ou permanência dos moradores nas áreas privadas da chapada e dos eucaliptais. Na verdade, a proibição se estende a circulação pessoas nos campos de eucalipto, pois a empresa alega questão de "segurança patrimonial".

Tradicionalmente, conforme Paula Andrade (2012), as famílias dos povoados produzem e manejam vias de circulação, chamadas por elas de caminhos e varedas, pelas quais circulam e, se orientam: até os outros povoados, os cemitérios, as áreas de roça, os locais de caça, dentre outros. Desenvolvem, assim, um sistema de orientação todo próprio, permitindo que alimentem um mapa mental (MAUSS, 2003) de áreas muito mais amplas e extensas do que aquela efetivamente ocupada por seus locais de residência e de trabalho.

As chapadas era o lugar onde camponeses podiam criar animais, da pequena pecuária, no regime de solta, onde engordavam seus bichos com capim nativo. A chapada, também, representava, o uso exclusivo dos camponeses, que tinham sobre seus recursos um direito de uso em comum, onde todos os membros de uma comunidade podiam extrair os recursos necessários da terra e das águas.

A silvicultura no Baixo Parnaíba significa a degradação dos distintos ambientes (chapadas, matos, baixos, carrascos, corpos hídricos), repercutindo diretamente sobre o modo de vida é caracterizado pela articulação sistemática e estratégica de diversas atividades econômicas (agricultura, extrativismo, pequena criação de animais, pesca, artesanato) e pela lógica jurídica de articulação entre uso comum e apropriação familiar dos recursos naturais, a destruição desses recursos implica em atingir no âmago a reprodução social desses grupos.

Da mesma forma como as demais monoculturas configuram como um novo modelo de "desenvolvimento", implantadas numa região onde antes encontravam-se terras devolutas e onde já haviam povoações de famílias camponesas. Quanto à questão ambiental, segundo os especialistas da área, o eucalipto por se tratar se uma árvore exótica ao cerrado maranhense pode provocar grande desequilíbrio aos recursos florestais, hídricos e pedológicos. 


\section{A chapada era, ao mesmo tempo, de ninguém e de todo mundo, era uma terra coletiva, costumeira e indivisa}

As chapadas, de acordo coma taxonomia nativa, são áreas tidas como abertas e altas, árvores dispersas, com poucos cursos d'água e, historicamente, vêm sendo utilizadas pelas famílias camponesas para a criação de pequenos animais e de bovinos, assim como para a caça e o extrativismo vegetal. (GASPAR; PAULA ANDRADE, 2014, p. 112). As chapadas são, também, caracterizadas por:

A chapada é quando a gente enxerga longe, quando é chapada. (...) É onde fica mais limpo, onde tem aquele capim grosso, as plantas nativas, é mais salteado carrasco é aquele que pega fogo todos os anos, ai todos os anos cria aquele mato. (Morador ${ }^{10}$ de Todos os Santos, Urbano Santos. Entrevista concedida em outubro de 2016).

Na chapada são encontradas diversas espécies vegetais, tais como: pitomba de leite (Pouteria ramiflora); candeia (Gochnatia polymorpha); goiabinha (Cordigera concolor); murici rasteiro (Byrsonima verbacifolia); murici (Byrsonima crassifólia (L.) Rich); mangaba (Mangaba); jatobá (Hymenaea stigonocarpa); pequi (Caryocar brasiliense); araticum (Annona Montana); Fava d'anta (Dimorpvhandra mollis); algumas são comestíveis para humanos de alimentação para animais da pequena criação. Também pode ser encontrada uma infinidade de ervas medicinal: amora (Morus); ameixa (Eriobothrya japônica); aroeira (Schinus terebinthifolius); hortelã (Mentha); angico (Anadenanthera macrocarpa); mangaba brava (Capparis speciosa griseb); Capim d'anta (Panicum prionitis); Ipê roxo (Handroanthus avellanedae); Cajuí (Anacardium Humile); sambaíba (Curatella americana Linn); Batata purga (Operculina macrocarpus); açoita cavalo (Operculina macrocarpus) e a janaguba (Himatanthus obovatus).

Das espécies nativas a mais rentável, economicamente para ás famílias camponesas, é bacuri, fruto do bacurizeiro (Platonia insignis), árvore que pode atingir mais de $30 \mathrm{~m}$ de altura, com tronco de até $2 \mathrm{~m}$ de diâmetro. Sua madeira, considerada nobre, também tem variadas aplicações. Essa árvore ocorre naturalmente desde a ilha de Marajó, na foz do rio Amazonas, até o Piauí, seguindo a costa do Pará e do Maranhão. Esse fruto, pouco maior que uma laranja, contém polpa agridoce rica em potássio, fósforo e cálcio, que é consumida diretamente ou utilizada na produção de doces, sorvetes, sucos, geleias, licores, "farofa" e outras iguarias (HOMMA; CARVALHO; MENEZES, 2010, p. 41).

\footnotetext{
10 Por questões éticas, neste trabalho será preservado a idade do entrevistado.
} 
No Maranhão, bem como no Baixo Parnaíba, a coleta do fruto acontece nos meses de dezembro à março, período intenso da safra, a coleta é realizada quando os frutos maduros caiem do pé, geralmente, a coleta do bacuri é realizada nas primeiras horas da manhã. Todas as pessoas têm livre acesso aos bacurizeiros. Após a coleta, os frutos são quebrados e a polpa é extraída, de forma bastante artesanal, com tesouras e facas, atividade que envolve toda a família. As máquinas de despolpar frutas disponíveis no mercado não foram dimensionadas e/ou adaptadas para o bacuri. Depois a polpa é embalada em sacos plástico, congeladas até serem vendidas.

Os principais compradores em Urbano Santos desse produto são oriundos dos municípios vizinhos, como Mata Roma e Chapadinha, de onde segue para São Luís e até para São Paulo e Rio de Janeiro. Cada família extrai, em média, cerca de $200 \mathrm{~kg}$ da polpa, cada quilo é vendido, durante os primeiros meses da safra por $\mathrm{R} \$$ 10,00 , no fim da safra, o preço sobre para $R \$ 15,00$, durante todo esse período, essas famílias conseguem, com a venda, até $R$ \$3.000,00 (t. Em muitos casos, esse dinheiro é investido na compra de gado (reserva de valor), eletrodomésticos e motocicleta.

Nos últimos anos as áreas de babaçuais de Todos os Santos diminuíram, segundo os moradores do povoado, por causa da falta de água, tanto pela escassez, como em decorrência da seca do riacho Chibél, cujo começou a secar a desde os anos de 1980, período de implantação dos campos de eucalipto à montante das nascentes do riacho. O depoimento de seu M sobre a produção de babaçu expressa que,

\begin{abstract}
A produção caiu muito, por causa da falta de água. (...), as bajes estão pequenos, tudo por causa que não tem água, tem palmeira que tem de dois, três cachos que cai murchinho, que não tem áqua para produzir, aqui cai murcho, tem coco que o caroço que é só a pelinha, o motivo é que não tem água, pode quebrar que é só aquela pelinha, não dá pra nada, toda produção diminuiu. (Morador de Todos os Santos, Urbano Santos. Entrevista concedida em Outubro de 2016).
\end{abstract}

De acordo com Moura (1988) o campesinato padece para sobreviver no mundo cada vez inserido e dependente do capitalismo. Enfrenta tanto a ameaça de expropriação de sua terra de trabalho, que ocorre em determinados contextos e que significa a perda total de suas condições de reprodução, quanto uma expropriação gradual. Dessa forma, tanto a redução dos bacurizeiros nas chapadas, quanto a pouca produtividade das palmeiras de babaçu representam o que Milton Santos 
(1979) chama de "equilíbrios tradicionais rompidos e as parcelas de espaço, em que viviam anteriormente de acordo com uma dinâmica própria”. Sendo assim, é cada vez mais evidente a ameaça à autonomia dos trabalhadores camponeses, ao sistema econômico local próprio àquelas famílias é dotado de peculiaridades do sistema econômico dos trabalhadores.

Com relação à criação de animais, principalmente bovinos e suínos, é feita solta nas áreas de formações florestais conhecidas como Chapadas, Carrascos e Capoeiras em áreas de uso e de exploração comum, usualmente de domínio público, sem cercas ou demarcação, com abundância de alimento para os animais. O costume é semelhante ao dos Faxinais existentes no Norte de Santa Catarina e Sul do Paraná há mais de um século. Como nos Faxinais, desde a década de 1980, na região se acentuam os conflitos devidos às mudanças nas estruturas e no uso dos recursos.

Propícias para a pequena pecuária, as capoeiras são áreas em pousio, deixadas periodicamente sem utilização para a agricultura, permitem o desenvolvimento da mata secundária ou são utilizadas para a criação de animais. Como observa Andrade (1979, p. 109):

\footnotetext{
Tanto a formação das capoeiras como o uso para o pastoreio, se este não for muito intenso, são favoráveis à renovação do solo em substâncias perdidas durante o período em que foi cultivada. Assim, a agricultura associada a pecuária, e as famosas rotações de terra ou culturas, são favoráveis à conservação do solo e, até certo ponto, à preservação do meio natural.
}

Em Todos os Santos, a criação de animais da pequena pecuária é de suma importância pra sua reprodução material, a criação, como vimos, é realizada principalmente, nas chapadas são áreas abertas e altas, sem muitas árvores, com poucos cursos d'água e, historicamente, foram utilizadas, principalmente, para a criação do rebanho bovino, Os animais pastavam livremente elas e outros espaços, a partir de regras pactuadas entre os vários grupos vizinhos (GASPAR, 2010; PAULA ANDRADE, 2012).

Na tabela abaixo, de acordo com dados do Censo Agropecuário/IBGE (2006), é possível identificar o maior número de estabelecimentos agropecuários com criação de bovino por estabelecimento de agricultura familiar ${ }^{11}$, significativo em

11 O IBGE entende por agricultura familiar conforme a Lei 11.326. Disponível em: <http://www.planalto.gov.br/ccivil_03/_ato2004-2006/2006/lei//11326.htm>. Acesso em: 4 de janeiro de 2019. 
relação ao da agricultura não-familiar, da mesma forma, que o número de cabeças, a diferença é bastante expressiva em Urbano Santos.

\section{Tabela 01: Número de estabelecimentos agropecuários com bovinos e número de cabeças de bovinos por agricultura familiar e não familiar em Urbano Santos (2006)}

\begin{tabular}{c|c}
\hline Agricultura familiar & № \\
\cline { 2 - 2 } Estabelecimentos agropecuários com bovinos (Unidades) & 139 \\
\hline Número de cabeças de bovinos (Cabeças) & 1.127 \\
\hline Tgricultura não familiar & $\mathbf{1 . 2 6 6}$ \\
\hline Estabelecimentos agropecuários com bovinos (Unidades) & 5 \\
\hline Número de cabeças de bovinos (Cabeças) & 217 \\
\hline Total & $\mathbf{2 2 2}$ \\
\hline
\end{tabular}

Fonte: IBGE - Censo Agropecuário (2016).

Outro grave impacto sobre a reprodução social e material das famílias camponesas do Baixo Parnaíba é o impedimento da criação de animais, tanto os de médio porte, como suínos e caprinos, quanto os de grande porte como bovinos e asininos. Este, segundo a autora, é um golpe violento sobre a economia camponesa, que não sobrevive apenas do cultivo, mas tem nesses animais uma reserva de valor, a ser acionada em momentos específicos - de necessidade, de festas e outros ${ }^{12}$.

Com a diminuição das áreas de chapada e, consequentemente, a diversidade de plantas e flores, cujas abelhas necessitam para a produção de mel. Diante disso, as abelhas migram para outras áreas, não voltam para os cortiços, como podemos observar no trecho dessa entrevista ${ }^{13}$ :

Não teve muita flor (...). Aí diminuiu a produção de mel, a gente tira, a gente vai ao cortiço tirar mel, não tem mel (...). Não tem porque a bichinha não tem onde caçar mel porque tá destruída a chapada (...). Destruída e aí quando, e quando não tem mel assim, quando ela não arruma, ela sai do cortiço e vão embora. (Morador de Todos os Santos, Urbano Santos. Entrevista concedida em outubro de 2016).

A propriedade privada, segundo Porto-Gonçalves (2012), "priva quem não é proprietário e, assim, constitui a escassez como base da economia. Priva da riqueza, a começar pela própria natureza com a propriedade privada da terra". Além do impedimento da circulação dos animais, os chamados gaúchos passaram a

\footnotetext{
12 Conforme colocado por Paula Andrade (2012), Chayanov (1966; 1981), Shanin (1976; 1979; 1983) e Wolf, $(1955 ; 1959 ; 1976 ; 1983)$ dentre outros.

${ }^{13}$ Entrevista realizada pela Profa. Maristela de Paula Andrade em março de 2012.
} 
exterminar fisicamente os porcos, burros, jumentos, bodes e bois das famílias, muitas vezes com requintes de maldade, não apenas atirando neles, mas por vezes envenenando-os, queimando-os, esquartejando-os ou utilizando-se de outros métodos cruéis, como atirar no ânus dos animais (PAULA ANDRADE, 2012, p. 179).

No caso do povoado Todos os Santos, a circulação de animais pelos campos de eucalipto não é impedida, porém não há mais com o que os animais se alimentarem, pois a vegetação típica da chapada foi removida, onde antes havia capim agreste, importante para o gabo, bem como a garampara e outros sem número de frutos. Enquanto que os eucaliptos, no qual nenhum animal da pequena criação camponesa se alimenta, está ai o fato que justifica a "livre circulação".

Desta forma, está cada mais difícil para os camponeses manterem a criação desses animais, pois são obrigados a manterem os presos, em currais ou quintas, sendo assim, onerando bastante os seus donos, já que aumenta significativa as despesas, onde antes buscavam na chapada e carrasco seu alimento, o trabalhador rural passa a adquirir ração para os mesmo. Segundo Oliveira (1987) os camponeses que antes dispunham coletivamente dos bosques, tiveram que passar a comprar tudo que lá outrora buscavam gratuitamente.

Além da extração do mel das abelhas nativas nas chapadas, existe a criação de abelhas como atividade econômica realizada pelos camponeses de Todos os Santos, as abelhas da espécie teúba (Melipona fasciculata Smith) são capturas nas chapadas em troncos ocos de madeira chamados de cortiços, segundo depoimento de um trabalhador rural, a atividade é muito lucrativa, não dá despesas.

Com a diminuição das áreas de chapada e, consequentemente, a diversidade de plantas e flores, cujas abelhas necessitam para a produção de mel. Diante disso, as abelhas migram para outras áreas, não voltam para os cortiços, como podemos observar no trecho dessa entrevista ${ }^{14}$ :

Não teve muita flor (...). Aí diminuiu a produção de mel, a gente tira, a gente vai ao cortiço tirar mel, não tem mel (...). Não tem porque a bichinha não tem onde caçar mel porque tá destruída a chapada (...). Destruída e aí quando, e quando não tem mel assim, quando ela não arruma, ela sai do cortiço e vão embora. (Morador de Todos os Santos, Urbano Santos. Entrevista concedida em outubro de 2016).

No trabalho de campo, realizado em outubro de 2016, a situação era a mesma, segundo relatos dos camponeses, as empresas proíbem o acesso e/ou

\footnotetext{
${ }^{14}$ Entrevista realizada pelo autor do artigo.
} 
permanência dos moradores nas áreas privadas da chapada e dos eucaliptais. $\mathrm{Na}$ verdade, a proibição se estende a circulação pessoas nos campos de eucalipto, pois a empresa alega questão de segurança patrimonial.

Tradicionalmente, conforme Paula Andrade (2012), as famílias dos povoados produzem e manejam vias de circulação, chamadas por elas de caminhos e varedas, pelas quais circulam e, se orientam: até os outros povoados, os cemitérios, as áreas de roça, os locais de caça, dentre outros. Desenvolvem, assim, um sistema de orientação todo próprio, permitindo que alimentem um mapa mental (MAUSS, 2003) de áreas muito mais amplas e extensas do que aquela efetivamente ocupada por seus locais de residência e de trabalho.

\section{As lutas camponesas pela manutenção na terra: uma rebrotação de esperanças entre chapada, carrasco e mato no Baixo Parnaíba}

O movimento camponês não se limita a luta pela terra. Mesmo quando essa é a reinvindicação principal, ele compreende outros ingredientes: a cultura, a religião, a condição camponesa entram na formação e desenvolvimento das suas reinvindicações e lutas. Mais do que isso. Pode-se dizer que a luta pela terra é sempre e, ao mesmo tempo, uma luta pela preservação, conquista ou reconquista de um modo de vida de ser e de trabalho. Todo um conjunto de valores culturais entra em linha de conta como componente do modo de ser e viver do camponês (IANNE, 2016, p. 66).

Os camponeses precisam se organizar em ligas, para superarem suas dificuldades, ou seja, em uma organização coletiva do campo ou numa organização social da produção. Assim, poderão um dia resolver seus problemas através da socialização entre os camponeses e de uma organização forte para enfrentar o capitalismo - em face das empresas (KAUTSKY, 1972).

O povoado São Raimundo, em Urbano Santos, por exemplo, tem uma história de luta pela permanência na terra, unidos, os camponeses dessa comunidade conseguiram se destaca pela defesa de sua área, um exemplo de luta em toda região do Baixo Parnaíba maranhense. Eles cuidavam porque a comunidade de São Raimundo os aguardava desde cedo para iniciar o dia de encerramento do projeto "Comunidade Tradicional e a Sustentabilidade do Extrativismo do Bacuri".

No final de 2015, a SMDH, com participação de representantes do poder público municipal, poder legislativo, INCRA, SEMA, SMDH, STTR, MPF, 
associações rurais do município e militantes ativistas pelos direitos humanos, reuniram-se como proposta de discutir o Projeto de Rebrotamento de bacurizeiros nativos estava preste acontecer. O objetivo do projeto é o manejo das técnicas desenvolvidas para o rebrotamento do bacuri e suas características ímpares a partir de suas raízes; produção em curto prazo para aumento da renda familiar, além do reflorestamento de áreas desmatadas e aquelas não deveriam ser desmatadas. 0 projeto que está dando certo no Pará com as orientações dos técnicos da EMBRAPA-PA, pertente aplicar essas experiências no Baixo Parnaíba. Uma das ideias é desenvolver esse trabalho em uma comunidade da região de chapadas que cobre as comunidades vizinhas: Boa união, Santa Filomena, Bom Princípio e Bracinho.

Seguindo desse modo, periodicamente, as associações dos povoados de Urbano Santos têm promovido encontros com outros movimentos, com o interesse de reunir o máximo de associações. Já aderiram ao movimento, a Associação das Parteiras de Urbano Santos, a Associação de Jussara, a Associação de Mangabeirinha, a Associação dos Anajás dos Garcês, a Associação da Boa União, a Associação de Bom Princípio, o Projeto de Assentamento Baturités, a Entrerrios, o STTR de Urbano Santos, o Fórum Carajás, o Fórum da Amazônia Oriental e dentre outras entidades.

Há um projeto proposto à Câmara de Vereadores de Urbano Santos, no qual recomenda a proibição do avanço das plantações de eucalipto e soja no município ${ }^{15}$. A proposta partiu de iniciativas populares, principalmente das comunidades diretamente atingidas, junto ao Sindicato dos Trabalhadores e Trabalhadoras Rurais/STTR de Urbano Santos. O Projeto de Lei segue em negociações/estruturação. Para tal, o sindicato, em parceria com a Sociedade Maranhense de Direitos Humanos/SMDH, assessoria jurídica para propor o corpo do projeto. Iniciativa semelhante e, inspiradora, aconteceu nos municípios de Barreirinhas e Belágua, também no Baixo Parnaíba, cujos projetos foram aprovados e, assim, há proibição de instalação e/ou expansão de plantação de monoculturas.

Um dos efeitos do estudo demandado pelo Fórum em defesa da Vida do Baixo Parnaíba (FDVBP) e da Sociedade Maranhense de Direito Humanos (SMDH) resultou na ação do Ministério Público Federal no Maranhão. Em 2017 a justiça atendeu à solicitação do MPF/MA e suspensão determinou que a Suzano interrompa

${ }^{15}$ Segundo informações dos camponeses de Todos os Santos, o projeto incluiu, ainda, a doação de parte das terras aos "pobres". 
o processo de desmatamento do cerrado maranhense e de implantação de novas florestas de eucalipto, em razão de impactos ambientais provocados pelo cultivo de eucalipto na região, com ressalva à manutenção dos plantios já existentes. O MPF/MA propôs também ação contra o Estado do Maranhão, IBAMA e a empresa Suzano Papel e Celulose S.A, por conta dos impactos causados pela expansão dos plantios de eucalipto na região do Baixo Parnaíba, com autorização da Secretaria de Estado do Meio Ambiente e Recursos Naturais (SEMA).

Em todos os Santos, houve o broto que se tornou um fruto saboroso, os camponeses reivindicaram e, após muita "briga", parte das terras adquiridas pela empresa forma "doadas" para a comunidade. Sobre essa doação assim se expressa um camponês:

\begin{abstract}
Essa parte aqui eles doaram pra comunidade, eles tomam depois eles doam, um pedaço pra comunidade porque a comunidade brigou com eles. Eles deram pra comunidade esse pedaço aqui, bem aqui também, eles deram aqui um pedaço pra comunidade aqui, bem aqui. Não chegou no pico de data porque a distância é muito grande, é longe demais. Dacolá pra cá é muito longe, do pico de data. Eles deram um pedaço aqui pra comunidade também. aqui pra associação, aqui pra comunidade aqui é diferente. (...) E bem daqui, do pico de data aqui, bem assim aqui tem um pedaço da pedra grande... a briga foi muito forte pra pedra grande ganhar esse pedaço aqui. (Morador de Todos os Santos, Urbano Santos. Entrevista concedida em março de 2016).
\end{abstract}

Depois que a máscara do "desenvolvimento" caiu, maioria dos moradores de Todos os Santos, tornaram-se as contra empresas produtoras de eucalipto. Conforme, o camponês, informante principal, que gentilmente me forneceu a maior parte das informações campo ressaltou o seguinte "eu sou contra, nós somos pobres, mas tem que comer arroz com feijão, farinha, alimento, é só pra eles, só serve pra eles, só beneficia a firma, nós não, os pobres não".

Recentemente as Comunidades de Bracinho e Baixão da Coceira, ambas pertencentes ao município de Santa Quitéria do Maranhão, receberam o título de posse da terra através do ITERMA. Fruto de resistência e luta destas comunidades em prol do direito à terra e à vida. A propósito, essas vitórias tão emocionantes dos camponeses do Baixo Parnaíba, só foram possíveis graças ao encorajamento dos moradores de ambos os povoados, juntos com os movimentos sociais (CPT, SMDH, STTR, FDBPM, dentre outras), elas representam a rebrotação da esperança. Desejo esta dissertação sirva, para muito além da obtenção de um título acadêmico, que ajuda, de qualquer forma, as outras comunidades que ainda sonham com o título definitivo da terra, que possam continuar com essa força, coragem, luz que tanto 
admiro e orgulha. Une-nos, somente juntos podemos vencer, desta maneira, continuar nas chapadas, carrasco e matos.

\section{Considerações Finais}

As plantações de eucalipto crescem acompanhando a demanda do comércio nacional e internacional. Com isso eclodem também a busca por mais áreas voltadas às grandes produções visando atender estes mercados. No entanto, esta expansão significa um panorama de injustiças sociais, cujas famílias camponesas estão perdendo o direito de viver e também injustiça ambiental, cria as condições para a construção de uma situação de insegurança das famílias, já que as atinge fortemente na sua estruturação social e econômica, além dos eminentes constrangimentos a que estão submetidas, resultante dessa ação devastadora.

A monocultura chegou, assim, aos grandes sertões e, com ela, a homogeneização Porto-Gonçalves (2012) de uma região que se caracteriza por sistemas de uso múltiplo das formações florestais, de um convívio equilibrado de uma enorme riqueza de ambiental onde as famílias camponesas, estão secularmente estabelecidas.

Percebeu-se que o avanço das indústrias agroflorestais no Baixo Parnaíba contribuiu decisivamente para profundas mudanças do cotidiano das atividades dos trabalhadores rurais que antes tiravam da roça o sustento de sua família e produziam alimentos, agora se veem venderem suas forças de trabalho para empresas proprietárias dos eucaliptais, neste caso o grupo empresarial SUZANO Papel e Celulose e MARGUSA S/A. Outros trabalhadores, sem mais alternativas, migram definitivamente para as periferias das pequenas, médias e grandes cidades como Urbano Santos, Chapadinha, São Luís ou mesmo, trabalhar em outras regiões do país.

Contrariando os "planejadores desenvolvimentistas", conforme vemos em vários estudos de impacto ambiental, e especificamente naquele da MARGUSA, ao se referirem a esses grupos, como caóticos, atrasados, sem planejamento, como utilizadores irracionais dos recursos naturais, na verdade, representa um sistema muito complexo de manejo dos recursos, totalmente apropriado aos ecossistemas locais. E, através da produção social do espaço, conseguem se reproduzir, social, moral, cultural e economicamente. 
Ao destruir com correntões a vegetação característica da região, além de provocar um desequilíbrio sem precedentes nos ecossistemas locais, atingindo fauna e flora de diversos tipos e portes, recursos hídricos importantes, a expansão dos plantios homogêneos provoca problemas sociais dramáticos, sobretudo, dos recursos hídricos, pois as lagoas e lagos já estão sofrendo processo de assoreamentos como no caso do rio Chibél, em Todos os Santos, já secaram, causando um dano de proporções incalculável, tanto na questão ambiental, como na questão social, refletindo-se também negativamente nas atividades econômicas (pesca, agricultura, extrativismo, caça, artesanato).

Registra-se, também, processo de desertificação e de erosão acelerada do solo com a retirada da cobertura vegetal; o desmatamento florestal da área atinge, ainda, outras atividades camponesas como: agricultura roças de mandioca, milho e arroz, bem como a coleta de ervas medicinais, de frutos como o bacuri e o pequi e madeira que leva ao extermínio da fauna ligada à caça, pesca e pequena criação e animais. Todos esses recursos discutidos ao longo do trabalho são fundamentais à reprodução camponesa do povoado Todos os Santos.

Esta situação de certa maneira vai acarretar na desarticulação da economia dos camponeses da região, pois em função do desmatamento das áreas de chapada para o plantio de eucalipto nas proximidades dos povoados, provocará o impedimento da criação dos animais livremente nestes locais. Tendo em vista que a economia desses camponeses é fruto de uma articulação entre a atividade agrícola, o extrativismo e a pequena criação de animais.

Contudo, com a mobilização, luta e união, os camponeses de Todos os Santos, assim como bem o fizeram os de São Raimundo, seguir o bom exemplo de sobrevivência diante da violenta concorrência pela terra e, sobretudo pela permanência nesta, mantendo-a como terra de trabalho, terra da vida, terra de reprodução social.

\section{REFERÊNCIAS}

ACIOLY, Luciana; PINTO, Eduardo Costa; LEÃO, Rodrigo Pimentel Ferreira. A China na nova configuração global: impactos políticos e econômicos. Brasília: Ipea, 2011.

ACSELRAD, Henri. As práticas espaciais e o campo dos conflitos ambientais. In: (Org.). Conflitos ambientais no Brasil. Rio de Janeiro: Relume Dumará: Fundação Heinrich Böll, 2004. 13-35. p. 
ANDRADE, Manoel Correia. Agricultura e Capitalismo. São Paulo: Ed. Ciências Humanas, 1979.

CARNEIRO, Marcelo Sampaio. Terra, trabalho e poder: conflitos e lutas sociais no Maranhão. São Paulo: Annablume, 2013.

GASPAR, Rafael B. O Eldorado dos gaúchos: deslocamento de agricultores do Sul do país e seu estabelecimento no Leste Maranhense. São Luís: Dissertação de Mestrado em Sociologia, PPGCSOC/UFMA, 2010.

GASPAR, Rafael Bezerra. O eldorado dos gaúchos: deslocamento de agricultores do Sul do país e seu estabelecimento no Leste Maranhense. São Luís: EDUFMA, 2014. 180 p.

HOMMA, A. K. O; CARVALHO, J. E. U. de; MENEZES, A. J. E. A. de. Bacuri: fruta amazônica em ascensão. Ciência Hoje, 2010.

IANNE, Otávio. A utopia camponesa. In: STEDILE, João Pedro. (Org.) A questão agrária no Brasil: interpretações sobre o camponês e o campesinato. São Paulo: Outras Expressões, 2016. p. 55-70.

IBGE - INSTITUTO BRASILEIRO DE GEOGRAFIA E ESTATÍSTICA. Censo Agropecuário 2006. Rio de Janeiro: IBGE, 2006. Disponível em: https://www.ibge.gov.br/estatisticasnovoportal/economicas/agricultura-e-pecuaria/21814-2017-censo-agropecuario.html. Acesso em: 02 de jan. de 2019.

Censo Demográfico 2010. Rio de Janeiro: IBGE, 2010. Disponível em: https://ww2.ibge.gov.br/home/estatistica/populacao/censo2010/default.shtm. Acesso em: 7 de dez. de 2018.

Produção da Extração Vegetal e da Silvicultura. Disponível em: https://www.ibge.gov.br/estatisticas-novoportal/economicas/agricultura-e-pecuaria/9105producao-da-extracao-vegetal-e-da-silvicultura.html?=\&t=0-que-e. Acesso em: 03 de jan. de 2019.

KAUTSKY, Karl. A questão agrária. Rio de Janeiro: Laemmert, 1968.

LÉVI-STRAUSS, Claude. Anthropologie Structurale Deux. Paris: Plon, 1973

MASSEY FERGUSON. “Gaúchos” descobrem novo eldorado no Maranhão. Disponível em: Noticiado em: 02 nov. 2007. Acesso em: 5 jan. 2019.

MAUSS, Marcel. "Ensaio sobre a dádiva: forma e razão da troca nas sociedades arcaicas". In:__. Sociologia e Antropologia. São Paulo: Cosac Naify, 2003. p. 183-314.

MESQUITA, B. A. O desenvolvimento desigual da agricultura: a dinâmica do agronegócio e da agricultura familiar. 1. ed. São Luís: EDUFMA, 2011. v. 1. p. 114.

MOURA, Margarida Maria. Camponeses. $2^{2}$ ed. São Paulo: Ática, 1988.

OLIVEIRA, Ariovaldo Umbelino de. A agricultura camponesa no Brasil. 4ª Ed. - São Paulo: Contexto, 2001.

Modo de produção capitalista e agricultura. São Paulo: Ática, 1987. 
PORTO-GONÇALVES, C. W. A globalização da Natureza e a Natureza da Globalização. 3ª edição. Rio de Janeiro: Civilização Brasileira, 2012.

SANTOS, Milton. Economia espacial: críticas e alternativas. São Paulo: HUCITEC, 1979.

SILVA, José Graziano da. A modernização dolorosa: estrutura agrária, fronteira agrícola e trabalhadores rurais no Brasil. Rio de janeiro: Zahar, 1981.

WOLF, Eric. Sociedades Camponesas [1966]. Rio de Janeiro: Zahar, 1976.

\section{NOTAS DE AUTOR}

\section{CONTRIBUIÇÃO DE AUTORIA}

Adielson Correia Botelho - Concepção. Coleta de dados, Análise de dados, Elaboração do manuscrito, revisão e aprovação da versão final do trabalho

Francisco Amaro Gomes de Alencar - Concepção e elaboração do manuscrito. Coleta de dados Participação ativa da discussão dos resultados; Revisão e aprovação da versão final do trabalho.

\section{FINANCIAMENTO}

Adielson Correia Botelho foi bolsista de mestrado da Fundação Cearense de Apoio ao Desenvolvimento Científico e Tecnológico (FUNCAP), a quem é grato pela ajuda provida a realização deste trabalho.

\section{CONSENTIMENTO DE USO DE IMAGEM}

Não se aplica

APROVAÇÃO DE COMITÊ DE ÉTICA EM PESQUISA

Não se aplica

\section{CONFLITO DE INTERESSES}

Não se aplica

\section{LICENÇA DE USO}

Este artigo está licenciado sob a Licença Creative Commons CC-BY. Com essa licença você pode compartilhar, adaptar, criar para qualquer fim, desde que atribua a autoria da obra.

\section{HISTÓRICO}

Recebido em: 01-02-2019

Aprovado em: 16-03-2019 